\title{
An educational electronic package on retention of CPR knowledge in residents of Anesthesiology
}

\author{
Mohammad Mireskandari ${ }^{1}$, Maryam Peimani ${ }^{2}$, Kianoosh Hosseini $^{3}$, \\ Fardin Yousefshahi ${ }^{4}$, Roya Padmehr
}

\begin{abstract}
Context: Nowadays, it is argued that educators can no longer rely on traditional teaching methods and more effective learner-centered education techniques are required. This study sought to assess retention of knowledge after ACLS workshop, comparing those who had used an educational electronic package as an adjunct to the lecture method, and with those who had not.

Methods: There were 48 residents of anesthesiology were assigned to intervention and control group at the beginning of their residency in 2009and 2010. In the intervention group, all subjects were asked to review the content of an educational electronic package for 3 weeks before the ACLS workshop. The ACLS workshop was held as the previous conventional method. The acquisition of ACLS knowledge was assessed by a questionnaire before and immediately after the workshop and the retention of knowledge by the same questionnaire 6 , and 12-months later. The differences between mean scores were determined with independent t-test.
\end{abstract}

Results: The mean score in the intervention group was $14.21 \pm 1.97$ vs. $10.25 \pm 2.55$ in the control group after 6 months $(P<0.001)$. The results showed a difference between the 2 groups. It was only significant with respect to test score of 6-months after the workshop. A year later both groups almost reached the same point.

Conclusion: This study showed the educational electronic package as an adjunct to the lecture method can be used as an aid to recall and a reinforcement technique to significantly enhance residents' retention of the ACLS course for a short period of time. However, more researches are needed.

Keywords: Education, Teaching materials, Retention, CPR

\section{Introduction}

Since the establishment of clinical skills lab center in Tehran University of Medical Sciences, regular and ongoing CPR training

\footnotetext{
${ }^{1}$ Imam khomeini Hospital, Tehran University of Medical Sciences, Anesthesiologist (MD)

${ }^{2}$ Endocrinology and Metabolism Research Center, Tehran University of Medical Sciences. Researcher(Msc.)

${ }^{3}$ Tehran Heart Center, Tehran University of Medical

Sciences, Cardiologist (MD)

${ }^{4}$ Tehran Heart Centre, Tehran University of Medical

Sciences. Anesthesiologist (MD)

${ }^{5}$ Baharloo Hospital. Tehran University of Medicine

Sciences. Obstetrician Gynechologist (MD)

Corresponding author:

Fardin Yousefshahi,

Tehran Heart Center, Tehran University of Medical Sciences, Anesthesiologist (MD) Tehran Heart Center,

North Kargar \& Al-Ahmad Cross,

Tehran, Iran; Postal Code: 1411713138

E-mail: yousefshahi@tums.ac.ir
}

workshops have been held for different classes of learners, including interns and residents in different professional disciplines. Although the impact of these training courses on the survival rate of patients and hospital discharge rates is unknown, Advanced Cardiac Life Support (ACLS) training is considered an important part of CPR training (Dane, 2000; Camp, 1997).

A large number of literatures in recent years have assessed the efficacy of resuscitation training and pointed out that skills and knowledge declined over time (Cooper, 1997; Sanders, 1994). In other words, ACLS scores significantly decreased in the first year after certification, so more frequent refresher training is needed (Pottle, 2000). Thereby, the American Heart Association (AHA) recommends that those whose daily work requires knowledge and skills in ACLS should not only be trained in ACLS, but also be given a refresher course at least every 2 year (Hazinski, 2005).
8

Epub ahead of print 
However, poor knowledge and skill retention following CPR training for medical staff has been documented over the past 25 years (Hamilton, 2000; Hammond, 2000). Many factors such as: inadequate training and practice in hospital wards, inefficient education, inappropriate or insufficient content of CPR workshop, time interval between instruction and practice in real situation, lack of hospital supervision on CPR steps, lack of adequate feedback and ineffective educators have been proposed to have negative effect in this field (Kidd, 2007; Broomfield, 1996).

On the other hand, factors like ongoing CPR training, simple education, training using multimedia devices and feedback provided by educators could have positive effects on knowledge and skill retention (Osteen, 1996; Stross, 1983).

It is important to determine the retention time of knowledge after CPR training in order to design ACLS training programs and refresher courses especially for medical staffs employed in critical care areas (Young, 2000). Furthermore, it is apparent that an appropriate approach to ACLS training necessarily needs methods which can improve learning and recalling in clinical situations (Kidd, 2007).

Method of resuscitation training in clinical skill lab center of medical school in Tehran University of Medical Sciences is lecture based along with showing educational film and then practicing on mannequins. This method of training and great volume of theoretical content presented during lecture may cause participants to get tired. Finally, it may lead to less efficient training (Kaye, 1998; Semeraroa, 2006).

Nowadays, it is argued that educators can no longer rely on traditional teaching methods and more effective learner-centered education techniques are required (Billi, 1993; Kimaz, 2006). For instance, some studies have revealed that multimedia interactive (computer-aided learning) can meet many of the important conditions for adult learners, like flexibility in time and location (Christenson, 1998; Batcheller, 2000). Therefore, currently, in many centers different teaching methods are used to enhance efficacy of the programs of CPR training (Reder, 2006; Brannon, 2009; Smith, 2008). One method is using the educational package in electronic form. We aimed to assess the effect of an educational electronic package as an adjunct to the lecture method on knowledge acquisition and retention of ACLS training. In this study, we chose anesthesiology residents because they are engaged directly in the cardiopulmonary resuscitation in hospitals affiliated to Tehran University of Medical Sciences.

\section{Methods}

This is a quasi-experimental study which was carried out at the clinical skills lab center of Tehran University of Medical Sciences. Participants were first year anesthesiology residents in 2009 and 2010. After explaining the research goals to them, all participants signed a written consent form.

All residents were assigned to intervention and control group at the beginning of their residency. In order to control confounding factors, we just entered anaesthesiology residents. Because of the limitation in number of new residents in each year, our sample size in each group was 24 according to samples available. All subjects in the intervention group were given an educational electronic package and were asked to review the contents of this Compact Disk (CD) for 3 weeks before ACLS training workshop.

This electronic package consisted of the theoretical materials, the algorithms and educational films related to resuscitation which was provided in a CD. In fact it was the same material teachers provided in their lectures. The ACLS training workshop was held as previous conventional setting, including lecture and educational films in small groups of 5 residents for both groups (intervention and control group).

Theoretical materials were based on a quick review, asking and answering questions, and the troubleshooting method. The course contents were based on the AHA latest strategies.

The acquisition of ACLS knowledge was assessed by a questionnaire completed by participants before and immediately after the workshop and the knowledge retention was assessed by the same questionnaire completed by the subjects in 6-months, and 12 -months later. The first test served as a pretest to assess baseline knowledge. Residents were not informed about the time of tests and they were taken without prior announcement. The questionnaire included $20 \mathrm{MCQ}$ (Multiple Choice Questions) which were designed according to the AHA algorithms and translated into farsi and then content validity was assessed by taking experts opinion (anaesthesiologist, cardiologist, and emergency medicine). Reliability of the tool was checked using the test-retest and K- coefficient method. 
The difference between the scores of before and immediately after the workshop was considered as the knowledge acquisition and the difference between the scores of immediately after the workshop, while 6 or 12 months laters was considered as a marker of knowledge retention.

Data were expressed as simple count or mean $[ \pm S D]$. Statistical analysis of the patient's data from the two study groups was conducted using the independent t-test. Statistical calculations were performed using SPSS version 17.0 (SPSS Inc. Chicago, IL, USA).

\section{Results}

The questionnaires were completed by 48 anaesthesiology residents in skills lab center of Tehran University of Medical Sciences. There were 24 residents in the intervention group with the mean age of $35.04 \pm 4.32$ years and 24 in the control group with the mean age of $35.25 \pm 4.51$ years. Both groups were females $66.7 \%$ and $33.3 \%$ were males. The mean score in the intervention group before the workshop was $9.92 \pm 2.33$ vs. $9.42 \pm 3.06$ in the control group it was $(P=0.528)$. The mean score in the intervention group after the workshop was $16.21 \pm 2.44$ vs. $15.38 \pm 1.43$ in the control group $(P=0.157)$. Also after 6 months, the mean score in the intervention group was $14.21 \pm 1.97$ vs. $10.25 \pm 2.55$ in control group $(P<0.001)$. And the final test mean score (12-months) in intervention group was $11.75 \pm 1.82$ vs. $11.63 \pm 2.33$ in the control group $(\mathrm{P}=0.837)$. As shown in Figure 1, the difference between 2 groups was only significant with respect to test score of 6-months after the workshop. After one year, both group almost reached the same point.

Table1 shows inter-group differences in mean scores. As seen in this table, significant differences were found in the mean scores of the pre and post-workshop test, postworkshop test in compared to 6-months test later, post-workshop test in compared to test of 1year later, 6-months test in compared to test of 1 year later in the intervention group, the same results were obtained in the control group and the mean score of 6-months test in compared to test of 1 year later was insignificant.

Figure 1: Comparison between mean scores of two groups.

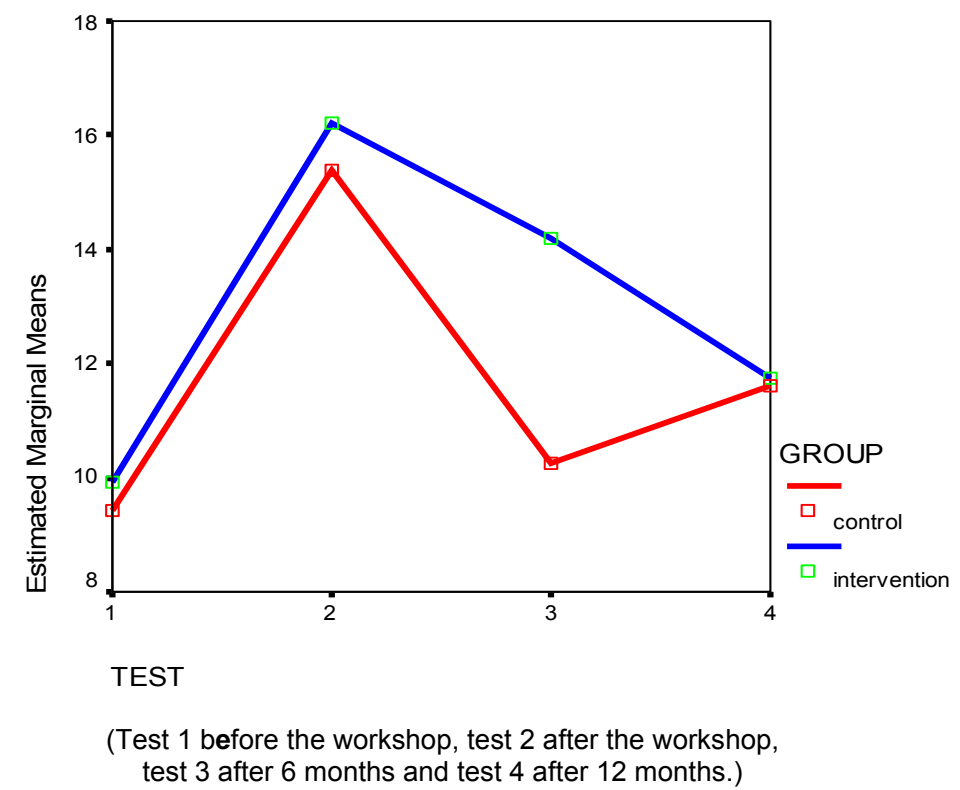


Table 1: Inter-group differences in mean scores

\begin{tabular}{|c|c|c|c|c|}
\hline & $\begin{array}{l}\text { Pre-Workshop and } \\
\text { Post-Workshop }\end{array}$ & $\begin{array}{l}\text { Post-Workshop and } \\
6 \text { Months Later }\end{array}$ & $\begin{array}{l}\text { Post-Workshop and } \\
\text { 1Year Later }\end{array}$ & $\begin{array}{l}\text { Six-Months and } \\
\text { one Year Later }\end{array}$ \\
\hline $\begin{array}{l}\text { Intervention } \\
\text { Group }\end{array}$ & $\begin{array}{l}\text { Mean difference: }-6.292 \\
\mathrm{P} \text { value }=.000 \\
\mathrm{Cl}:-7.366 \text { to } 5.217\end{array}$ & $\begin{array}{l}\text { Mean difference: } 2.000 \\
\mathrm{P} \text { value }=.000 \\
\mathrm{Cl}: 1.329 \text { to } 2.671\end{array}$ & $\begin{array}{l}\text { Mean difference: } 4.458 \\
\mathrm{P} \text { value }=.000 \\
\mathrm{Cl}: 3.502 \text { to } 5.415\end{array}$ & $\begin{array}{l}\text { Mean difference: } 2.458 \\
\mathrm{P} \text { value }=.000 \\
\mathrm{Cl}: 1.587 \text { to } 3.330\end{array}$ \\
\hline $\begin{array}{l}\text { Control } \\
\text { Group }\end{array}$ & $\begin{array}{l}\text { Mean difference: }-5.985 \\
\mathrm{P} \text { value }=.000 \\
\mathrm{Cl}:-7.375 \text { to }-4.541\end{array}$ & $\begin{array}{l}\text { Mean difference: } 5.125 \\
\mathrm{P} \text { value }=.000 \\
\mathrm{Cl}: 3.961 \text { to } 6.289\end{array}$ & $\begin{array}{l}\text { Mean difference: } 3.750 \\
\mathrm{P} \text { value }=.000 \\
\mathrm{Cl}: 2.535 \text { to } 4.965\end{array}$ & $\begin{array}{l}\text { Mean difference: - } \\
1.375 \\
{ }^{*} \mathrm{P} \text { value }=.099 \\
\mathrm{Cl}:-3.031 \text { to } .281\end{array}$ \\
\hline
\end{tabular}

$* \bar{P}>0.05$ was statistically non-significant

\section{Discussion}

In recent years, a variety of educational techniques have been utilized to promote knowledge retention of ACLS (Hagyard, 2007; Filgueiras, 2006). This study sought to assess acquisition and retention of knowledge after ACLS workshop, comparing those who had used an educational electronic package with those who had not. In respect to knowledge acquisition, there was significant difference between pre and post workshop scores in both groups; showing that the workshop was successful in rising the level of ACLS knowledge among trainees. In regard to knowledge retention, there was significant mean difference between post-workshop test and sixth months test score in each group $(P<0.001)$. In other words, a decrease in score of sixth month test was observed in both groups compared to post-workshop test. Indeed retention of knowledge began to decline over a 6-months period of time in each group.

In this study, we also observed significant mean differences of score between postworkshop test and 12 months test in each group $(P<0.001)$ It appears that a decrease in score has been continued with time in both groups. Our findings are consistent with results of previous studies. Osteen et al. (1996) observed that ACLS scores significantly decreased among 40 registered nurses employed in the critical care wards during their first year after training. Noteworthy in this study, even in the group of conducting mock mega code scenarios, ACLS scores decreased after 6 months (Osteen, 1996). Smith et al. (2008) evaluated staff's retention of ACLS and BLS knowledge and skills by written and performance tests (initial, posttraining, and final testing). It was found that only $30 \%$ and $14 \%$ of participants passed ACLS tests taken at 3 and 12 months consequently (Smith, 2008). Settles et al.
(2011) compared two methods of teaching ACLS (traditional classroom instruction and classroom instruction plus practice with patient simulators). Their findings showed no significant differences in ACLS knowledge immediately after instruction or at 3 to 9 months post-training (Settles, 2011). The main finding of the present study was that knowledge score significantly remained higher in the intervention group in 6 months after the workshop comparing it to the control group. It seems that, to some extent, the educational electronic package could be able to enhance knowledge retention, but no longer than 6 months in the period of one year and after that there were no significant differences between the 2 groups.

The results also showed that while a significant decrease in knowledge score occurred in 12 months compared to 6 months in the intervention group $(P<0.001)$, this decrease was not statistically significant at the same time in the control group $(P=0.099)$. This finding again highlights that the educational electronic package can have positive effect on knowledge retention of ACLS and increase it for a short period of time.

Hence, this research suggests that ACLS training with using this electronic package should be carried out at least every 6 months to prevent deterioration of the knowledge (Stempien, 2009).

In the same line with our findings, AHA guideline recommends that those whose daily work requires knowledge and skills in ACLS such as anesthesiologists, should not only be trained in ACLS but also be given an updating training regularly (Kidd, 2007; Stempien, 2009). In this regards, Kaye et al. (1998) assessed a newly designed refresher course and showed that knowledge and skill improved immediately after refresher course and 2 to 4 months later but no longer than that (Kaye, 1998). 
In the published literature, we found many studies which have assessed the effect of different types of computer-based training on knowledge retention of ACLS compared to conventional methods (Christenson, 1998; Batcheller, 2000; Lee, 2010). For instance, Cheristenson et al. (1998) compared two methods of ACLS training (multimedia based method vs. standard method) and showed the similarity in the performance of the two study groups to some extent that the difference was not large enough to distinguish one method of education as superior (Christenson,1998). Moule et al. evaluated a BLS CD-ROM for a BLS test which was found to be adaptable and positively evaluated by most learners. The main drawback of this method was the inability of learners to interact with others which led to the fact that computerbased learning is a poor substitute for lecture based CPR training (Moule, 2001). However, we did not replace the CD-ROM with the ACLS lecture in our study; but used it as an adjunct to our current ACLS training program. Another study demonstrated that computer assisted training besides lecture based teaching could be more effective on knowledge and skill retention of ACLS (Fabius, 1994).

Also it should be mentioned that, the newest curriculum guidelines of the AHA for ACLS education have been adjusted based on selfdirected, case-based learning strategies. Educational electronic package besides lecture-based method, can be considered as an aided recall and reinforcing technique in order to facilitate learning and remembering knowledge in a more extended time (Darr, 2000). Moreover, the educational electronic package was a self-study one, It appeared to be an effective tool which provide availability to learners at any time (Hamilton, 2005). Stross (1983) carried out a study on 132 physicians who completed an ACLS course. These physicians were randomly allocated into a control group or one of two groups which receiving mailed periodic reprints (group1) or quarterly patient management problems (group2). In fact these interventions provided reinforcement of previously mastered knowledge and skills. All physicians were retested for knowledge and skills after one year. There were just significant differences in knowledge retention among groups. The knowledge retention in the control group was $52 \%$, while group $1,75 \%$ and group 2 averaged $82 \%$ (Stross, 1983). As mentioned earlier, reinforcing techniques need to be considered in order to boost knowledge retention specially at regular intervals (Darr, 2000).
In conclusion, our results showed that an educational electronic package can be used as an adjunct to the current method for ACLS training to anesthesiology residents and can significantly enhance their knowledge retention for a six months period. Reinforcement courses seem to be necessary after six month of a CPR education program. However additional research with a larger sample size and also in other groups of medical students are needed to confirm its effectiveness.

\section{References:}

Batcheller, A. M., Brennan, R.T., Braslow, A. et al. (2000) Cardiopulmonary resuscitation performance of subjects over forty is better following half-hour video self-instruction compared to traditional 4-hour classroom training, Resuscitation, 43, pp. 101-10.

Billi, J.E. \& Membrino, G.E. (1993) Education in adult advanced cardiac life support training programs: changing the paradigm, Ann Emerg Med, 22, pp. 457-83.

Brannon, T.S. \& White, L.A. (2009) Use of instructional video to prepare parents for learning infant cardiopulmonary resuscitation, Proc (Bayl Univ Med Cent), 22, pp. 133-7.

Broomfield, R. (1996) A quasi-experimental research to investigate the retention of basic cardiopulmonary resuscitation skills and knowledge by qualified nurses following a course in professional development, $\mathrm{J} A d v$ Nurs, 23, pp. 1016-23.

Camp, B.N., Parish, D.C. \& Andrews, R.H. (1997) Effect of advanced cardiac life support training on resuscitation efforts and survival in a rural hospital, Ann Emerg Med, 29 pp. 529-33.

Christenson, J., Parrish, K., Barabe, S. et al. (1998) A comparison of multimedia and standard advanced cardiac life support learning, Acad Emerg Med, 5(7) pp. 702-8.

Cooper, S. \& Cade, J. (1997) Predicting survival, inhospital cardiac arrests: resuscitation survival variables and training effectiveness, Resuscitation, 35, pp. 17-22.

Dane, F.C., Russell-Lindgren, K.S., Parish, D.C., Durham, M.D. \& Brown, T.D. (2000) In-hospital resuscitation: association between ACLS training and survival to discharge, Resuscitation, 47, pp. 83-7.

Darr, L.R. (2000) Advanced cardiac life support education: a self-directed, scenario-based approach, J Contin Educ Nurs, 31(3), pp. 11620.

Fabius, D.B., Grissom, EL. \& Fuentes, A. (1994) Recertification in cardiopulmonary resuscitation: a comparison of two teaching methods., J Nurs Staff Dev, 10(5), pp. 262-8. 
Filgueiras Filho, N.M., Bandeira, A.C., Delmondes, T. et al. (2006) Assessment of the general knowledge of emergency physicians from the hospitals of the city of Salvador on the care of cardiac arrest patients, Arq Bras Cardiol, 87(5), pp. 634-40.

Hagyard-Wiebe, T. (2007) Should critical care nurses be ACLS-trained? Dynamics; 18(4), pp. 28-31.

Hamilton, R. (2005) Nurses knowledge and skill retention following cardiopulmonary resuscitation training: a review of the literature, J Adv Nurs, 51(3), pp. 288-97.

Hammond, F. \& Saba, M. (2000) Advanced life support: retention of registered nurses' knowledge 18 months after initial training, Aust Crit Care, 13(3), pp. 99-104.

Hazinski, M.F., Nadkarni, V.M., Hickey, R.W. et al. ( 2005) Major changes in the 2005 AHA Guidelines for CPR and ECC. Circulation. 112(suppl), pp. IV-206-IV-211.

Kaye, W. \& Mancini, M.E. (1998) Teaching adult resuscitation in the United States - Time for a rethink, Resuscitation, 37, pp. 177-78.

Kidd, T. \& Kendall, S. (2007) Review of effective ACLS training using experiential learning, JCN, 16(1), pp. 58-66.

Kimaz, S., Soysal, S., Cimrin, A.H. \& Gunay, T. (2006) Assessment of physicians employed in emergency medical services about their level of knowledge on basic life support, advanced cardiac life support and medicolegal responsibilities, Ulus Travma Acil Cerrahi Derg, 12(1), pp. 59-67.

Lee, C.C., Im, M., Kim, T.M. et al. (2010) Comparison of traditional ACLS course instruction Vs. a scenario-based, performance oriented team instruction method for Korean paramedic students, J Emerg Med , 38(1), pp. 89-92.

Moule, P. \& Gilchrist, M. (2001) An evaluation of a basic life support CD-ROM, Health Informatics Journal, 7(1) pp. 29-36.
O'Steen, D.S., Kee, C.C. \& Minick, M.P. (1996) The retention of advanced cardiac life support knowledge among registered nurses, $J$ Nurs Staff Dev, 12(2), pp. 66-72.

Pottle, A. \& Brant, S. (2000) Does resuscitation training affect outcome from cardiac arrest? Accid Emerg Nurs, 8, pp. 46-51.

Reder, S., Cummings, P. \& Quan, L.(2006) Comparison of three instructional methods for teaching cardiopulmonary resuscitation and use of an automatic external defibrillator to high school students, Resuscitation, 69, pp. 443-53.

Sanders, A.B., Berg, R.A., Burress, M. et al. (1994) The efficacy of an ACLS training program for resuscitation from cardiac arrest in a rural community, Ann Emerg Med, 23, pp. 56-9.

Semeraroa, F., Signoreb, L. \& Cerchiaria, E.L. (2006) Retention of CPR performance in anaesthetists, Resuscitation, 68, pp. 101-108.

Settles, J., Jeffries, P.R., Smith, T.M. \& Meyers, J.S. (2011) Advanced cardiac life support instruction: dowe know tomorrow what we know today? J Contin Educ Nurs, 22, pp. 1-9. doi: 10.3928/00220124-20110315-01.

Smith, K. K., Gilcreast, D. \& Pierce, K. (2008) Evaluation of staff ś retention of ACLS and BLS skills, Resuscitation, 78, pp. 59-65.

Stempien, J. \& Betz, M. (2009) A prospective study of students and instructors opinions on ACLS course teaching methods, CJEM, 11(1), pp. 5763.

Stross, J.K. (1983) Maintaining competency in advanced cardiac life support skills. JAMA, 249(24), pp. 3339-41.

Young, R. \& King, L. (2000) An evaluation of knowledge and skill retention following an inhouse advanced life support course, Nurs Crit Care, 5(1), pp. 7-14. 